\title{
Teaching Test-Taking Strategies: Importance and Techniques
}

\author{
Hamzeh Dodeen \\ United Arab Emirates University, UAE
}

\begin{abstract}
Test-taking strategies are cognitive abilities to deal with any testing situation well independently of the knowledge of the test content. Examples are managing time effectively, surveying all questions before responding, dealing with difficult questions, dealing with multiple-choice questions, and underlying keywords questions. This paper has two goals. First, reviewing and discussing the direct and indirect importance of teaching test-taking strategies on students' performance: Directly, these strategies help students increase their scores on tests through the effective use of their time, effort, and test conditions. Indirectly, using appropriate test-taking strategies affects other factors such as reducing test anxiety and improving attitudes toward tests; second, suggesting teaching techniques to help teachers, educators, and test developers systematically teach test-taking strategies: More than 50 techniques for teaching the main test-taking strategies have been introduced in question formatting. These techniques could be taught with any content or materials and at any school level.
\end{abstract}

Keywords: testing skills, test-taking strategies, testing strategies, testing techniques, teaching testing skills

\section{Introduction}

Tests are the most common assessment tools in most of the educational systems in the world. Whether students like them or not, this is a fact and they have to deal with them. Nowadays, the importance of tests has become beyond schools. Many critical decisions that affect people's life are made based on specific tests. Considering these issues, all efforts should be done to help test-takers in general and students in particular do well in their tests.

Test-taking strategies are cognitive abilities to deal with any testing situation in appropriate manner and to know what to do during tests. Examples of these strategies are managing time effectively, surveying all questions before responding, solving easy questions first, checking and reviewing answers, underlying key words or concepts in questions, eliminating wrong options, and others. These strategies help students do well in tests independently of the knowledge of the test content or materials (Sarnacki, 1979). All students can benefit from test-taking strategies, and this is especially true for low ability students. Moreover, some argue that test-taking strategies are as important as having the basic knowledge and information to answer the test questions (Langerquist, 1982). However, this does not mean that these strategies can replace knowledge of the materials or the preparation for the test; but it rather means that having such strategies helps students maximize their scores to the limit allowed by the level of their knowledge and preparation for the test. In fact, one of the most important test-taking strategies is to know how to study and to prepare well for the test.

Observing students taking tests shows that some of them, who have enough knowledge or have prepared well, do not perform well in their tests. This is due to the fact that not only ability affects students' performance 
in tests, but also several psychological, cognitive, and personal factors, for example, subject matter, level of test anxiety, attitudes toward the subject of the test, general attitudes towards tests, and test-taking strategies (Hambleton, Swaminathan, \& Rogers, 1991).

\section{Importance of Test-Taking Strategies}

Some students do poorly in test because of the lack of test-taking strategies or the use of poor ones. These strategies have both direct and indirect effects on students' performance. Directly, these strategies help students increase their scores on tests through the effective use of their time, effort, and test conditions. Indirectly, using appropriate test-taking strategies affects other related but important factors such as reducing test anxiety and improving students' attitudes toward tests.

Testing strategies help students translate their knowledge from classroom learning (McLellan \& Craig, 1989). Students who have or acquire test-taking strategies or skills will positively affect their testing competency and, hence, their academic performance. Studies indicate that those students with test-taking strategies: (1) have improved attitudes toward tests; (2) have lower levels of test anxiety; and (3) achieve better. Even students who are familiar with the subject matter may do poorly in tests because of the lack of test-taking skills (Sweetnam, 2003).

Test-taking strategies can be used to effectively help examinees cope with the problem of test-anxiety. Test-anxiety is "feeling of tension and anxiety that interferes with the ability to communicate what one knows in a test situation" (Austin, Partridge, Bitner, \& Wadlington, 1995, p. 10). Test anxiety is a fairly common problem in students especially at the college level (Chang, 1986). According to Hembree (1988), more than $20 \%$ of college students experience this problem with tension or uneasiness occurring before, during or after an exam. While a reasonable level of test-anxiety is useful to motivate students to do better in tests, a high level of test-anxiety may interfere with how student's perform (Strnad, 2003) and negatively affect his/her concentration, organizing of ideas and thoughts, understanding of questions, and retrieving of keywords. Highly anxious students generally have poor test-taking strategies. They, for example, spend much more time in irrelevant thoughts rather than on the tasks, and they usually have poor study habits (Culler \& Holahan, 1980). Also, they do poorly on essay questions and take-home tests and they have difficulties in multiple-choice verbal items (Culler \& Holahan, 1980; Rocklin \& Thompson, 1985).

Tests are usually designed to assess students' knowledge in particular content or materials. When other factors affect students' performance, test scores are no longer valid measures of students' knowledge or ability levels. Test-taking strategies can improve the overall validity of the test scores so that they accurately reflect what students really know. This could be done by ensuring that students lose points only because they do not know the information and not for unrelated reasons. Ebel (1965) stated that "More error in measurement is likely to originate from students who have too little, rather than too many, skills in test-taking" (p. 3).

\section{Teaching Test-Talking Strategies}

The effect of teaching test-taking strategies on students' performance was investigated by several studies. For example, Dolly and Williams (1986) investigated the effect of teaching test-taking strategies on improving students' scores on exams. Test-taking strategies used in the study included: selecting the correct option by guessing, the strategies of the length option, the similarities or oppositeness, and deduction. These strategies were given on a one-hour lecture/discussion to 25 sophomore students who enrolled in education class. The 
performance of these students was compared with that of a control group (29 students) who received nothing by using a 48-item test. Results indicated that students in the experimental group outperformed students in the control group.

Sweetnam (2000) investigated the relationship between teaching test-taking strategies and improving classroom test scores. The study was applied on 22 fourth grade students (10 girls and 12 boys) who were taught specific test-taking strategies in a weekly workshop for a semester long. Test-taking strategies used included motivation, relaxation techniques, and actual test strategies. Students were encouraged to use these strategies in each test given in school. Results showed a significant gain in students' scores when measured at the end of the year using ITBS (Iowa Test of Basic Strategies).

As a part of a study about sex differences in test-taking strategies for problem-solving on math, Gallagher (1992) examined the hypothesis that differences in test performance on math between males and females are the results of differences in the students' strategies for solving math problems. Subjects were high-scoring examinees on the SAT-mathematics. Results showed significant differences in strategies used by males and females in math tests.

Vattanapath and Jaiprayoon (1999) investigated the effectiveness of teaching test-taking strategies for multiple-choice tests on achieving higher scores in English tests. Sixty first year nursing students participated in the study. The experimental group received training in test-taking strategies for 10 weekly sessions, each was 20 minutes. At the end of the semester, groups' performance was compared using a 40-item multiple-choice test. It was found that the experimental group outperformed the control group. Participants also developed positive attitudes toward the learning of test-taking strategies and started to use them in real testing situations.

Carraway (1987) studied the effect of teaching a test-taking seminar on decreasing test anxiety and increasing test scores. Level of test anxiety was measured using TAI (the Test Anxiety Inventory) developed by Spielberger (1980). Using experimental and control groups from 30 nursing students who enrolled in a community college, it was found that students who participated in the seminar had significantly lower level of test anxiety and significantly higher test scores than students who did not participate.

As for improving attitudes toward tests, few studies have been conducted on the effect of teaching test-taking strategies. For example, Birenbaum and Feldman (1998) studied students' attitudes toward two test formats: open-ended and multiple-choice and learning and test-taking strategies. Several instruments that measure attitudes toward assessment formats, learning-related characteristics, academic self-concept, and test anxiety were applied on a sample of 58 university students. Results indicated that students with good learning strategies prefer the open-ended format over the choice type. In addition, high anxious students tend to prefer the multiple-choice type over the constructed-response type.

Eggleston (1988) studied the relationship between students' attitudes toward test and their achievement using a sample of 49 freshmen college students. It was found that attitudes toward tests may cause underachievement. Perney and Ravid (1990) investigated the relationship between academic performance in statistics and students' attitudes toward tests. The study was conducted on a sample of 68 students in a master's degree program. Results indicated that there is a moderate positive correlation between attitudes toward tests and achievement.

Dodeen and Abdelmabood (2005) examined the effect of teaching test-taking strategies on students' performance, test anxiety level, and attitudes toward tests. Two female sections ( 24 and 23 students) who study an English course at UAEU (the United Arab Emirates University) participated in this study. Students were taught by one instructor specific test-taking strategies for dealing with multiple-choice items in English tests 
over a period of six weeks (10 teaching hours). The results of this study showed decreasing in students' scores between the midterm and the final exam. This result was interpreted by the unexpected difficult level of the final exams. The test-taking strategies that students learned were not able to compensate for the difficulty of the tests. As for the test-anxiety level, the mean of students' level of test-anxiety in the first section before teaching the test-taking strategies was 51.31 and it was 46.25 after teaching. This change was significant $\left(t_{19}=2.39, p<\right.$ 0.05). Similar results were obtained for the second section. As for students' attitudes toward tests, the overall mean of students' attitudes toward test improved from 49.00 to 51.20 for the first section, and from 46.5 to 47.56 for the second section.

\section{Techniques for Teaching Test-Taking Strategies}

Taking many tests in life does not guarantee the achievement of skills or strategies to deal with any testing situation in appropriate manner. These strategies can be achieved by teaching them in a systematic manner, exactly as the case with any other discipline. Moreover, because these strategies are transferable strategies and affect achievement on all other subjects, there is a need to give more time and training in teaching these strategies so students will have enough opportunities to learn and practice them. Unfortunately, teaching such strategies or skills is usually ignored in schools in general and particularly at the elementary level where these strategies are best to be taught. The best thing that happens in some schools in this regard is providing students with some instructions or guidelines about how and what to do in tests especially before or during final exams. Definitely, this is not enough for students to achieve and apply these strategies.

To help teachers, educators, and test developers teach students and test takers how to deal with tests wisely, and to help students develop test-taking strategies, some training techniques have been suggested. Table 1 summarizes the suggested techniques for each of the main test-taking strategies.

Table 1

Suggested Techniques for Teaching Test-Taking Strategies

\begin{tabular}{|c|c|}
\hline Test-taking strategy & Teaching techniques \\
\hline \multirow{5}{*}{ Predicting test questions } & Write questions (different types) on each chapter/unit you finished studying \\
\hline & Predict questions (different type) for the next test \\
\hline & Answer your predicted questions \\
\hline & Answer the predicted questions provided by other students \\
\hline & Think of some difficult questions on the next test \\
\hline \multirow{5}{*}{$\begin{array}{l}\text { Reading test instructions } \\
\text { carefully }\end{array}$} & Read test instructions and answer questions about them \\
\hline & Write appropriate instructions for a test \\
\hline & Match instructions and questions \\
\hline & Write instructions for specific type of questions \\
\hline & Find mistakes in these tests instructions \\
\hline \multirow{8}{*}{$\begin{array}{l}\text { Skimming the whole test } \\
\text { first }\end{array}$} & Rank-order the following test questions from the easiest to the most difficult \\
\hline & Estimate the time needed to answer each section on the test \\
\hline & Estimate the time needed to answer each question on the test \\
\hline & Find the easiest question on the test \\
\hline & Find the hardest question on the test \\
\hline & Find questions that give clues to answering other questions on the test \\
\hline & Note the total grade of the test and the grade for each question \\
\hline & Which question that has the highest grade and the lowest \\
\hline
\end{tabular}


Table 1 to be continued

\begin{tabular}{|c|c|}
\hline Test-taking strategy & Teaching techniques \\
\hline \multirow{8}{*}{ Time management } & Read the test and answer only the easiest question \\
\hline & Write only the outlines of your answers to these essay questions \\
\hline & In this exercise you have five questions in separate papers handed on an answer every three minutes. \\
\hline & Answer this question in three minutes (assuming that the answer normally needs six minutes) \\
\hline & Answer these five questions in 20 minutes (assuming that the answers normally need 25 minutes) \\
\hline & Answer these five questions in 15 minutes (assuming that the answers normally need 25 minutes) \\
\hline & $\begin{array}{l}\text { You have } 15 \text { minutes to answer the following three questions, write how much time you need to } \\
\text { answer each one, answer them and then compare you expected time with actual time }\end{array}$ \\
\hline & $\begin{array}{l}\text { Questions are written on separate papers, answer each question and hand on it, then move to the other } \\
\text { question }\end{array}$ \\
\hline \multirow{6}{*}{$\begin{array}{l}\text { Answering } \\
\text { multiple-choice questions }\end{array}$} & Answer the following multiple-choice questions without looking at the options/alternatives \\
\hline & Answer the following multiple-choice questions by eliminating the wrong/nonsensical answers \\
\hline & $\begin{array}{l}\text { For each multiple-choice question, rank order the four options (a, b, c, and d) according to its } \\
\text { correctness level }\end{array}$ \\
\hline & For each multiple-choice question determine if there is only one correct answer or a best answer. \\
\hline & $\begin{array}{l}\text { Answer the following multiple-choice questions by using the following strategy: If what you know } \\
\text { does not fit, what you do not know must fit }\end{array}$ \\
\hline & $\begin{array}{l}\text { If two options in a multiple-choice question are very similar, then both must be wrong or the option } \\
\text { (all of the above) is the answer. Check this out for the following questions }\end{array}$ \\
\hline \multirow{4}{*}{ Guessing } & $\begin{array}{l}\text { Answer the following multiple-choice questions by guessing the wrong answer (educated or } \\
\text { intelligent guess not blind guessing) }\end{array}$ \\
\hline & Avoid second-guessing, guessing on your guessing, because it is often wrong \\
\hline & Eliminate one wrong option in each of the following multiple-choice questions \\
\hline & Eliminate two wrong options in each of the following multiple-choice questions \\
\hline \multirow{3}{*}{$\begin{array}{l}\text { Never leave an answer } \\
\text { blank }\end{array}$} & Speed test 1: answer the following 10 questions in five minutes \\
\hline & Speed test 2: answer the following 15 questions in five minutes \\
\hline & Speed test 3: answer the following 20 questions in five minutes \\
\hline \multirow{7}{*}{$\begin{array}{l}\text { Dealing with difficult } \\
\text { questions }\end{array}$} & Rewrite each of the following questions in your language \\
\hline & Underline the keywords in each of these questions \\
\hline & For each question, write your answer plan or idea (do not answer the question) \\
\hline & Write your best answer to the following questions (moderate difficulty) \\
\hline & Write your best answer to the following questions (difficult) \\
\hline & Write your best answer to the following questions (very difficult) \\
\hline & Estimate (in percentage) how confident you are about the answer of each of the following questions \\
\hline \multirow{7}{*}{ After test review } & What was the question's main source in this test? Textbook, notes, handouts...? \\
\hline & Have you expected your grade on this test? Was it accurate? \\
\hline & Was the test difficult, moderate, or easy for you? \\
\hline & Have you checked your mistakes in the test? \\
\hline & What was the best thing you did in this test? \\
\hline & What was the worst thing you did in this test? \\
\hline & Are you going to prepare for the next test in the same way? \\
\hline
\end{tabular}

The suggested techniques could be taught with any content or materials and with any school level. Of course, as it is often true, the earlier we learn important or useful skills, the better for us to apply them in tests and real situations. It is also important to time all exercises, tests, or assignments used in teaching these strategies, and to strongly stick with it because time is a major factor in any test. 


\section{References}

Austin, J. S., Partridge, E., Bitner, J., \& Wadlington, E. (1995). Prevent school failure: Treat test anxiety. Preventing School Failure, 40(1), 10-13.

Birenbaum, M., \& Feldman, R. A. (1998). Relationships between learning patterns and attitudes towards two assessment formats. Educational Research, 40(1), 90-97.

Carraway, C. (1987). Determining the relationship of nursing test scores and test-anxiety levels before and after a test-taking strategy seminar. (ERIC Document Reproduction Service No. ED 318 498).

Chang, M. K. (1986). Test anxiety and academic achievement. Paper presented at the Second Regional Conference on University Teaching, Las Cruces, NM.

Culler, R. E., \& Holahan, C. J. (1980). Test anxiety and academic performance: The effect of study-related behavior. Journal of Educational Psychology, 72, 16-20.

Dodeen, H., \& Abdelmabood, H. (2005). The effect of teaching test-taking strategieson university students' performance, test anxiety, and attitudes toward tests. In P. Davidson, Ch. Coombe, \& W. Jones (Eds.), Assessment in the Arab world (pp. 193-203). Dubai, UAE: TESOL Arabia.

Dolly, J., \& Williams, K. (1986). Using test-taking strategies to maximize multiple-choice test scores. Educational \& Psychological Measurement, 46, 619-625.

Ebel, R. (1965). Measuring education achievement. New Jersey: Prentice-Hall.

Eggleston, M. H. (1988). Freshmen attitudes and the college placement test. (ERIC Document Reproduction Service No. ED 324 584).

Gallagher, A. (1992). Sex differences in problem-solving strategies used by high-scoring examinees on SAT-M. (ERIC Document Reproduction Service No. ED 352 420).

Hambleton, R. K., Swaminathan, H., \& Rogers, H. J. (1991). Fundamentals of itemresponse theory. Newburg Park: Sag Publications.

Hembree, R. (1988). Correlates, effects, and treatment of test anxiety. Review of Educational Research, 58, 47-77.

Langerquist, S. (1982). Nursing examination review: Test-taking strategies. Addison-Wesley Publishing Company, MenloPark, C.A..

McLellan, J., \& Craig, C. (1989). Facing the reality of achievement test. Education Canada, 36-40.

Perney, J., \& Ravid, R. (1990). The relationship between attitudes toward statistics, math self-concept, test anxiety, and graduate students achievement in an introductory statistics course. Paper presented at the Annual Meeting of the American Educational Research Association, Boston, M.A..

Rocklin, T., \& Thompson, J. M. (1985). Interactive effects of test anxiety, test difficulty, and feedback. Journal of Educational Psychology, 77, 368-372.

Sarnacki, R. E. (1979). An examination of test-wise in the cognitive test domain. Review of Educational Research, 49, $252-279$.

Spielberger, C. D. (1980). Test anxiety inventory: Preliminary professional manual. Palo Alto, C.A.: Consulting Psychologist Press.

Strnad, K. (2003). Coping with college series: Handling test anxiety. Retrieved from http://www.counseling.ilstu.edu/files/down loads/articles/coping-test_anxiety.pdf

Sweetnam, K. R. (2003). Test-taking strategies and student achievement. Retrieved from http://www.cloquet.k12.mn.us/chu/ class/fourth/ks/stratigies.htm

Vattanapath, R., \& Jaiprayoon, K. (1999). An assessment of the effectiveness of teaching test-taking strategies for multiple-choice English reading comprehension tests. Occasional Papers, 8, 57-71. 